\title{
Acting Contrary to Our Professed Beliefs, or the Gulf Between Occurrent Judgment and Dispositional Belief
}

\author{
Eric Schwitzgebel \\ Department of Philosophy \\ University of California at Riverside \\ Riverside, CA 92521-0201 \\ http://faculty.ucr.edu/ eschwitz \\ eschwitz at domain- ucr.edu \\ 9518274288
}

September 25, 2008

\begin{abstract}
:
We often act contrary to our professed beliefs. For example, someone might sincerely avow the intellectual equality of the races and yet nonetheless frequently act and react in ways that appear inconsistent with that belief. I argue that it is best to think of such cases as cases in which occurrent judgment diverges from dispositional belief, and in which the individual's belief state is "in-between", so that it's neither quite right to describe her as believing that the races are intellectually equal nor quite right to describe her as failing to believe that. Belief does not always flow passively from sincere judgment. In fact, many of our most morally important beliefs change only transiently, gradually, and with effort. Along the way, I suggest that there is no such thing as occurrent belief and that knowledge does not require belief.
\end{abstract}




\section{Acting Contrary to Our Professed Beliefs, or the Gulf Between Dispositional Belief and Occurrent Judgment}

Sometimes your words and actions don't mesh. Sure, you lie and you waffle - but that's just the start of it. With genuine conviction, complete sincerity, you endorse some proposition $-P$, let's call it. And every time you think about $P$, you reaffirm it; it seems unquestionably true. Yet, if we look at your overall arc of behavior - at your automatic and implicit reactions, at your decisions, at your spontaneous remarks on nearby topics there's a decidedly un- $P$-ish cast. What should we say you believe in such cases? This question is, or at least it should be (as I'll explain), central to moral psychology.

i.

Let's start with examples.

The implicit racist. Many Caucasians in academia sincerely profess that all races are of equal intelligence. Juliet, let's suppose, is one such person, a Jewish-American philosophy professor. She has, perhaps, studied the matter more than most: She has critically examined the literature on racial differences in intelligence, and she finds the case for racial equality compelling. She is prepared to argue coherently, authentically, and vehemently for equality of intelligence and has argued the point repeatedly in the past. Her egalitarianism in this matter coheres with her overarching "liberal" stance, according to which the sexes too possess equal intelligence, and racial and sexual discrimination are odious. And yet - I'm sure you see this coming - Juliet is systematically racist in her spontaneous reactions, judgments, and unguarded behavior. 
When she gazes out on class the first day of each term, she can't help but think that some students look brighter than others - and to her, the black students never look bright. When a black student makes an insightful comment or submits an excellent essay, she feels more surprise than she would were a white or Asian student to do so, even though her black students make insightful comments and submit excellent essays at the same rate as the others; and, worse, her bias affects her grading and the way she guides class discussion. When Juliet is on the hiring committee for a new office manager, it won't seem to her that the black applicants are the most intellectually capable, even if they are; or if she does become convinced of the intelligence of a black applicant, it will have taken more evidence than if the applicant had been white. When she converses with a janitor or cashier, she expects less wit if the person is black. And so on; you get the idea. Juliet may even be perfectly aware of these facts about herself; she may aspire to reform; she may not be self-deceived in any way. We might imagine that sometimes Juliet deliberately strives to overcome her bias in particular cases. She might try to interpret a black student's comments especially generously. But it's impossible to constantly maintain such self-conscious control, and of course condescension and patronizing, which her well-intentioned efforts sometimes become, themselves reflect apparent implicit assumptions about intelligence. ${ }^{1}$

\footnotetext{
${ }^{1}$ Juliet would presumably show impaired performance in classifying light-
} skinned faces with negative words and dark-skinned faces with positive words relative to the opposite classification in Implicit Association Tests of the sort that have recently been receiving considerable attention in psychology (and also in Zimmerman's [2007] and Gendler's [2008b] recent work on belief): See Nozek, Greenwald, and Banaji (2007) for 
The trembling Stoic. Having been won over by the Stoics, or by pessimists, or by believers in eternal glory - let's say by Stoics - Kaipeng quite sincerely judges, not just on one occasion but repeatedly, that death is not bad. He can recite arguments toward the conclusion, arguments he finds compelling and which he fully accepts as he makes them. Yet he trembles on the battlefield, and not just in anticipation of pain. He regrets the death of a good person, and not entirely on behalf of those who've lost the benefit of her company. He takes measures to forestall his own death, and not wholly from a sense of duty. His actions and reactions for the most part are indistinguishable from the actions and reactions of someone who considers death bad. Like Juliet, Kaipeng might be perfectly aware of these facts about himself and seek to change them; yet they remain mostly unchanged.

The cognitive non-cognitivist. Na has been reading Ayer and Hare. As a result, she embraces the non-cognitivist view that moral and aesthetic claims cannot literally be true or false. The opposing position seems to her mere hokum. But later, she finds herself implicitly assuming that moral and aesthetic claims do have truth value, both in her everyday interactions and in her immediate responses to philosophical arguments. She regards as simply mistaken her husband's claim that Budweiser tastes better than Guinness. In the audience at the next department colloquium, she innerly inveighs against a visiting speaker's "false" moral claims. As he lays down his radical

a review. "Racist" performance on tests of this sort alone may not be enough to justify describing someone as racist in the sense that Juliet appears to be, but it may at least call into doubt the depth of one's egalitarianism. If you have the nerve, you can test yourself for implicit racism, sexism, ageism, etc., at https://implicit.harvard.edu/implicit/demo/. 
consequentialist vegetarianism, a chorus of "false", "wrong", "untrue" sings through her inner thoughtfield. It's not that Na doubts her new position when she is explicitly reminded of it. She might even catch and correct herself periodically. But her dispositional profile - her tendency to respond in particular ways to particular situations is thoroughly permeated with aesthetic and moral cognitivism; that dispositional structure could not be overthrown in a day.

The forgetful driver. Ben reads an email saying that a bridge he normally takes to work will be closed for a month. He immediately realizes that he'll have to drive a different route. However, the next day he finds himself on the old route, heading toward that closed bridge. Of course, when he sees the bridge, he remembers the email. Maybe he smacks himself on the forehead at that moment. The day after, Ben does the very same thing again. If he were older, he'd say he was having a "senior moment" - but he's thirty. He also forgets to allow himself extra commute time. In lining up his chores, he neglects to consider that his new route takes him right by the dry cleaners, and he convinces his wife to get the cleaning for him.

The recent literature on belief is full of cases of this sort, and a minor industry has sprung up aiming to make sense of them. Though no one discusses exactly these cases, let's take the Juliet example as archetypal. Rowbottom (2007) suggests that Juliet flips back and forth between believing that the races are equally intelligent and believing they aren't. Zimmerman (2007) argues that Juliet consistently believes the races equally intelligent, with the contrary dispositions underwritten by something less than belief. Hunter (manuscript) argues that Juliet believes the races not to be of equal intelligence, though she wishes she believed otherwise. Gertler (forthcoming* [permission to cite 
needed]) suggests that Juliet believes both that the races are of equal intelligence and that they're not. Gendler (forthcoming-a\&b) argues that Juliet believes that the races are of equal intelligence, and also "alieves" - in some more primitive way - that they're not. I'll get further into these views in a bit.

What I would reject, but these other philosophers all seem to accept, is that in cases of this sort there are generally determinate facts about whether the subject believes or fails to believe the proposition in question. I would suggest, instead, that Juliet is somewhere between believing and failing to believe, so that it's not quite right either to say that she believes or to say that she fails to believe that all the races are of equal intelligence. We should jettison the impulse to think that questions about belief, in complicated cases, can always be answered with a simple yes or no. If someone is courageous on Tuesdays and cowardly on Wednesdays, we cannot - or should not - say either that he's courageous or that he's cowardly simpliciter. If a substance dissolves in water but not in oil, we shouldn't say either that it does or that it does not generally dissolve in liquids. Why not think of belief the same way, in cases of this sort? Some of the resistance to this idea arises, I suspect, from an insufficiently sharp distinction between occurrent judgment and dispositional belief.

ii.

Let's chat a bit about occurrences and dispositions, then. Here's one useful way to carve things up. An occurrence is an event - a particular event that transpires at a particular time and place. A disposition is a proneness or tendency to be involved, in a particular 
way, under particular conditions, in events of a particular type. A vial of Morton's salt dissolves in Lake Erie on July 3. That is an occurrence. Salt is also generally prone to dissolve in water (under particular conditions). Solubility in water is a disposition that salt possesses, a dispositional property of salt. Or: In college, Jamie read the Bible. In saying this, we can refer to a single, particular occurrence - a single (protracted) event of reading through the Bible - or we can intend, instead, to be imputing to Jamie a certain dispositional property, the property of having been a Bible reader, someone with a proneness or tendency to read the Bible.

Pronenesses differ from tendencies. Jamie did not in fact have the dispositional property of being a Bible reader if he did not on several occasions read (some portions of) the Bible, regardless of how prone he may have been to read the Bible, had circumstances been right. In saying he was a Bible reader, we attribute to him a (past) tendency or habit, requiring multiple instances of fulfillment. In contrast, a vase can be fragile - can have the dispositional property of being prone to break - even if it has never in fact broken. The mere aptitude to break, in counterfactual conditions, is enough to underwrite the dispositional ascription. Some dispositional ascriptions don't require multiple instances of fulfillment but still require one instance: She bench-presses 200 pounds. Philosophers haven't always carefully distinguished these types of dispositional ascription. $^{2}$

2 But see Ryle's (1949) nuanced treatment. His distinction between "capacities" and "tendencies" is similar to, but not identical with, the distinction I draw here between pronenesses and tendencies. Fara (2005) is also helpfully nuanced. 
I put my claim about Jamie - that he read the Bible - in the past tense because the ambiguity between dispositional and occurrent trait attributions tends to dissolve in the present tense. We say, dispositionally, that Jamie reads the Bible, or occurrently that he is reading the Bible. We say, dispositionally, that Corina runs a six-minute mile, or, occurrently, that she is running a six-minute mile. Though I make no claims about deep grammar, I've noticed that in the present tense, English marks the dispositional/occurrent distinction fairly well (more so than many other languages).

Returning to belief, then, we say, dispositionally, that Armando believes that New York City may not exist in 200 years and, occurrently, that Armando is believing that New York City may not exist in 200 years. Wait - no we don't! Why does my word processor mark that last italicized phrase as a grammatical error? My computer marks no error - and there is no violation of ordinary usage - when I write that Armando is guessing that New York City may not exist in 200 years. Does Microsoft know what my colleagues $^{3}$ mostly deny - that "believe" has no occurrent use? Let's try Google, perhaps a more beneficent company (setting aside some concerns about privacy and China). When I enter "is believing" I find instance after instance of "seeing is believing" - but of course that phrase is not the present progressive characteristic of ongoing occurrences. If I exclude pages with the word "seeing" I still find only phrases with the same structure: "hearing is believing", "skiing is believing" "cc-ing is believing", not a present progressive in sight.

\footnotetext{
${ }^{3}$ Burge (1979), Fodor (1987), Kim (1998), and Williamson (2000), just to name a
} few. 
But we philosophers needn't be chained by grammar (or worse, Microsoft's grammar checker). The argument from Google doesn't yield apodictic metaphysics. Let's look at the sense. Jamie does not constantly read the Bible. He ceases sometimes. He is a Bible reader because he has a tendency, occasionally, to read the Bible for a while, after which he stops reading. Likewise, at the end of her workout, Corina completely ceases to run. If Armando has the dispositional property of believing in the impermanence of New York City because he is disposed to occasional fits of occurrent belief in its impermanence, then what are we to say when his fits are over? That he ceases to believe (but still believes in a dispositional sense), as Corina ceases to run (but still runs in a dispositional sense) and Jamie ceases to read (but still reads in the dispositional sense)? Now we butt up not just against the grammar checker but against robust folk-psychological intuition: Armando does not in fact cease to believe in the impermanence of New York City when his mind turns to other things (when he is no longer "occurrently believing" it). He continues to believe, without recess. So there's a structural difference here - a difference between Armando's believing and Corina's running. Structurally, it's not a typical case of a term with both a dispositional and occurrent sense. ${ }^{4}$

\footnotetext{
${ }^{4}$ See Crane (2001) for a similar argument. For a psychological example, we
} might compare fear. Consider: "Julia fears snakes". Though it is awkward to say that Julia "is fearing" the snake she now presently sees, we can naturally say, occurrently, that she "is feeling fear" or "is afraid". The dispositional attribution of fear of snakes to Julia may be tantamount to attributing a tendency (not just a proneness) toward short episodes of occurrent fearing. Thus, it may structurally parallel the dispositional attribution of 
This suggests, perhaps, that if we are not to overthrow common sense and grammar - which despite my attraction to iconoclasm I think we shouldn't do lightly we should embrace the idea that believing is not an event of short duration, something that transpires briefly and is then over, like morning runs and Bible-reading sessions. Being a believer is not a matter of being disposed toward short bursts of belief that quickly expire in the same way that being a runner means being disposed to go running for a while. If believing is an occurrence or event at all, it is one of long duration, less like the event of running than like the event of being a runner. ${ }^{5}$

It might seem that I'm quibbling. When philosophers say that someone "occurrently believes" something, I think I know more or less what they mean. There are nearby words with occurrent uses: "is thinking", "is judging"; we could take occurrent belief as roughly synonymous with those. (But note: The occurrent use of "think" diverges considerably from the dispositional.) Furthermore, when a disposition manifests itself - when the thing that tends to or is prone to occur actually does occur - that manifestation is an occurrent event. Perhaps we could think of the vase's breaking as

being a runner or a Bible reader. Once the snake is gone, Julia ceases feeling fear, ceases being afraid, but still fears snakes in the dispositional sense. Other attributions of fear, however, such as "Armando fears that a nuclear weapon will be detonated in a large U.S. city within the next fifty years" may be relatively unconnected to particular episodes of feeling afraid, may be more revealed in Armando's answers to certain questions, his decisions about where to live, his attitudes toward homeland security, etc. Attributions of this latter sort more closely parallel attributions of belief, as I see it.

${ }^{5}$ See Lewis (1986) on events. 
occurrent fragility and then similarly describe Armando's judging that New York may not exist in 200 years as occurrent belief? Why stickle at a word? Why not allow belief to be given an occurrent sense in technical philosophy of mind?

Here's the problem. "Occurrent belief" implies - or sounds like it implies and is generally taken to imply - actual belief. We don't call breakage "occurrent fragility" because (as my nine-year-old son has amply demonstrated to me) not all things that break are fragile (or even, perhaps, breakable). Likewise dispositional belief isn't always present, I'd like to suggest, whenever there are occurrences of the type of mental event most naturally interpreted as the referent of the phrase "occurrent belief" - events that I would call judgments, that is, passing affirmations or endorsements or takings as true of particular ideas or propositions. The usage of the phrase "occurrent belief" thus occludes an interesting set of phenomena, cases in which, as I would put it, judgment is insufficient for belief - cases like those with which I began this essay (see also Schwitzgebel 2001, 2002). ${ }^{6}$

iii.

${ }^{6}$ Bach (1981) and Crane (2001) also argue against the idea of "occurrent belief”, contrasting belief and thinking much as I distinguish belief and judgment. I endorse their arguments but think mine go farther. Other interesting discussions include Swinburne 1985, Peacocke 1999, Frankish 2004, Shah and Velleman 2005, and Lawlor manuscript. It's perhaps worth noting that Audi, in his detailed 1994 treatment of occurrent belief, dispositional belief, and dispositions to believe, does not appear to envision cases of judging or "occurrently believing" something without thereby also believing it simpliciter. 
Dispositional approaches to belief are generally built upon a broad base. One way of developing this point is to say that they're not "single track" dispositions, in Ryle's terminology, but multi-track - they "signify abilities, tendencies or pronenesses to do, not things of one unique kind, but things of lots of different kinds" (1949, p. 118). For example, in Ryle's words,

to believe that the ice is dangerously thin is to be unhesitant in telling oneself and others that it is thin, in acquiescing in other people's assertions to that effect, in objecting to statements to the contrary, in drawing consequences from the original proposition, and so forth. But it is also to be prone to skate warily, to shudder, to dwell in imagination on possible disasters and to warn other skaters. It is a propensity not only to make certain theoretical moves but also to make certain executive and imaginative moves, as well as to have certain feelings (1949, p. 135; see also Price 1969; Schwitzgebel 2002).

Another way of developing the point is, as it were, to think of belief as having a single dispositional track, but a very wide track. Marcus (1990) says that to believe that $P$ is just to (in the right sorts of circumstances) act as if $P$ obtains; Hunter (manuscript) says that it is to act and react as if $P$ were the case. On either Ryle's view or the Marcus/Hunter view, we're faced with the question of what to do when a person appears to only partly possess the relevant dispositional structure - when he acts only in some 
respects as if $P$ obtains or is prone to do only some of the things characteristic of belief that $P^{7}$

In some such cases, there are what we might call "excusing conditions": He doesn't warn the other skaters because he doesn't see the other skaters or because he'd love to watch them fall through. Dispositional claims, like most generalizations, hold only ceteris paribus, "all else being equal", or only against a defeasible set of background assumptions. If Harold doesn't warn the other skaters because he wants them to fall in or because at that moment he happens to be having a grand mal seizure, that deviation from the typical dispositional manifestation counts not at all against ascribing him the belief that the ice is thin. But of course there must be limits to such excusers. Otherwise, we could save any generalization or dispositional ascription we wished, simply by excusing every counterinstance. Unfortunately, articulating the principles underwriting the limits on excusing conditions is a difficult task and beyond the scope of this essay. (I'd say, roughly, that when a candidate excusing condition would undermine the potential usefulness of the generalization, we should reject it as an excuser.) But perhaps you'll allow me this: Given that there must be limits on excusers, it seems unlikely to be an exceptionless law of nature that whenever a person is disposed in some crucial respects as a $P$-believer is disposed (or, as we might say, whenever someone to a substantial degree matches the dispositional stereotype for believing that $P$ ), that person must thereby be

\footnotetext{
${ }^{7}$ Some philosophers, however - e.g., Carnap (1947/1956), Sellars (1969), and de
} Sousa (1971) - express a temptation toward a narrower dispositional view, on which to believe is to be disposed only to avow. Whether they entirely yield to the temptation is another question. 
disposed in every respect as a $P$-believer is disposed, except when the ceteris paribus clause is legitimately sprung. There must, in other words, be cases in which the relevant disposition or dispositions are only partly possessed. There must, indeed, be something like a continuum between full possession of all the relevant dispositions and possession of none of them.

In non-belief cases where broad-track or multi-track dispositions are only partly possessed, careful descriptions refrain from simple attribution or denial. My computer is mostly stable but tends to be unstable when I've recently run a print job. Is it stable simpliciter? It may sometimes be appropriate to give a simple yes answer (my son wants to use it to play games on an airplane) or a simple no (a friend wants to borrow it to print her dissertation chapters), but the most careful and general response is not to say either that it's stable or that it's not, but rather to specify the conditions under which it is and is not likely to crash, hang, slow down, or garble a file. Villia is scrupulously honest, except about her dating life. Is she honest simpliciter? Again, neither a simple yes or no answer seems quite right, though in certain circumstances a simple yes or no will suffice.

If to believe is to possess a multi-track disposition or a broad-track disposition or (as I myself prefer to put it) a cluster of dispositions, then there will be "in-betweenish" cases in which the relevant disposition or dispositions are only partly possessed. And if we treat such cases analogously to other cases of the partial possession of multi-track or broad-track dispositions, then we should say of such cases that it's not quite right, as a general matter, either to ascribe or to deny belief simpliciter - though (as in the computer example) certain limited conversational contexts may permit simple ascription or denial. I'll soon argue that we should treat the cases of Juliet, Kaipeng, etc., as cases of this sort. 
Of course, not all approaches to belief are dispositional approaches.

Representational approaches are an important alternative (see Schwitzgebel 2006 for a review). On such approaches, to believe that $P$ is to possess, in a belief-like way, an internal representational token (perhaps a sentence in the language of thought) with the content $P$. However, the same considerations apply. Most representationalists are also functionalists: To be in a particular representational state is to be in a state that plays a certain functional role - a state apt to have been brought about in some particular set of ways and apt to produce certain outputs under certain conditions (Fodor 1968, 1987; Lycan 1986; Nichols and Stich 2003). Oversimplifying: To possess, in a belief-like way, the representation that $P$, is to have an internal tokening of a state that's apt to be brought about by perceiving or hearing or inferring that $P$ and that is apt to lead to avowals of $P$, is apt to promote action $A$ if it's discovered that that $A$ will achieve a much-desired goal if $P$ is true, and that is apt to be combined with other representations, such as "if $P$ then $Q$ " either to conclude $Q$ or as part of a reductio. There will necessarily be cases of partial match here, too: Some but not all aspects of the relevant functional role may be satisfied. A person may, for example, be in a state apt to bring about certain of the outputs but not others. Unfortunately, the images and metaphors often invoked by representationalists don't sit easily with gradualism: Talk of inserting language-like representations into "belief boxes", "memory stores", "file folders" etc., suggests a distinctly yes-or-no architecture. This is an infelicity of these metaphors, obscuring the fact that functional roles may be only incompletely filled.

iv. 
Back to Juliet. Does she believe that the races are intellectually equal? She is disposed to occurrently judge that the races are intellectually equal, but I suggest that, when speaking of her carefully and generally, we refrain from either ascribing or denying her the dispositional belief. In some contexts, a simple "yes, she does believe" will suffice for example, in predicting what she will say in a debate on the subject. In other contexts, a simple "no, she doesn't" may be appropriate. Imagine two black students who have been treated unfairly by her. One student might say to the other, quite legitimately it seems, that she doesn't think that black people are as smart as white people. He might say this, even knowing that Juliet sincerely avows the claim that they are equal. In the conversational context, what's important is not those avowals but other aspects of her behavior. The case, then, is similar to the case of my computer's stability: In a context where printing is the issue of focus, I can rightly say simply that my computer is not stable; if printing is a non-issue, I can rightly say that it is stable. The most careful and general description refrains from ascribing it either stability or instability simpliciter; and likewise the most careful and general description of Juliet refrains from either ascribing or denying her belief in the intellectual equality of the races.

Am I belaboring the obvious? I hope so. But it hasn't seemed obvious to any of the several capable philosophers who've recently been writing about cases of this sort, as I mentioned earlier. In the last two years, philosophers have nicely filled in the space of alternative views.

Should we say that Juliet, and Kaipeng, and Na, and Ben fully believe but can't bring themselves consistently to act in accord with their beliefs? Zimmerman argues for 
this view on the grounds that it would be strange to accuse someone like Juliet of being ignorant of the truth about the intellectual equality of the races or to attempt to reform her by further argument (2007, p. 79, adapting the example). Zimmerman is correct that to accept the view I'm proposing we'll probably have to grant that it might not be quite right to describe a person as believing that $P$, even though she is not ignorant of $P$ and doesn't need to be convinced of its truth. Maybe even worse - as I'll argue shortly - Juliet might know that $P$ and still not quite entirely believe it. One cost of the present view is the seeming unnaturalness of saying such things. Yet neither is intuition entirely on Zimmerman's side here: The black students seem to make no error when they say that Juliet doesn't really believe that all the races are equally intelligent. The view I'm proposing allows for that as a contextually adequate attribution; Zimmerman's view does not. $^{8}$

Gendler (forthcoming-a\&b) approaches such cases by distinguishing between belief and "alief". An alief is "an innate or habitual propensity to respond to an apparent stimulus in a particular way", paradigmatically "associative, automatic, action-generating, agnostic with respect to the existence of what it (re)presents, arational, typically affectladen" (forthcoming-b, p. 5). Like Zimmerman, Gendler argues that the implicit racist

${ }^{8}$ Zimmerman also argues against my earlier discussions of in-between cases of believing by seemingly committing to a view on which it is impossible to have vague cases of belief (p. 74-75). However, he presents no reasons I can discern to suppose that vague cases are impossible, unless perhaps he thinks they are impossible because they are difficult to describe using a standard logic that employs the law of the excluded middle (p. 75). 
does believe that the races are intellectually equal; Gendler goes beyond Zimmerman in offering a meatier account of the basis of the implicit racist's racist reactions. In cases like that of Juliet, Gendler suggests, a substantial range of behavior is driven by beliefdiscordant aliefs - habitual, automatic, and arational response patterns. Now while the category of alief may prove to be a useful one, I think it's a mistake to hive off, as Gendler seems to want, our rational and thoughtful responses from our habitual and automatic ones as though only the first were pertinent to belief. After all, we reason habitually, and our reasoning is deeply influenced by our automatic gut responses. Furthermore, our spontaneous and automatic reactions often seem to reflect considerable thought or implicit reasoning - especially in our social expertise and in the skillful flow of repartee. Pure reason and pure habit, if possible at all, are the exception, not the rule. It's artificial to try to pry them apart. I'd suggest that it's more natural, and it cuts the mind closer to its joints, to hold that we believe that $P$ if our actions and reactions generally seem to reflect a $P$-ish take on the world, whether those actions and reactions are spontaneous and automatic or deliberate and reflective. ${ }^{9}$

${ }^{9}$ I would not, however, deny that the man who stands trembling on a glass floor high in the air still believes that the glass floor is solid and can support him (to use one of Gendler's examples). The difference between this case and the Juliet case is that in Juliet's case there is a broad range of dispositions that seem to accord with the racist belief, while the range of dispositions in the glass floor case is narrow, so ceteris paribus excusers may be justified (or even if they're not, the deviation from the overall dispositional profile of a glass-floor-is-solid believer is small). Especially relevant here are epistemic dispositions - dispositions to make certain inferences and reach certain 
Gendler's principle argument against treating habitual and automatic responses as central to belief is this: Beliefs, by their nature, are meant to track the truth and to change in response to evidence. Aliefs do not change in this way; they change in response to (or should Gendler say they are constituted by?) changes in habit (forthcoming-b, p. 14). Juliet's explicitly avowed attitude about the races - that they are intellectually equal - is responsive to evidence. She developed it, presumably, upon seeing the evidence and would change it if contrary evidence came along. So it is this part of her psychology, and not her habits and spontaneous responses, that constitutes her belief. In response, I'd venture that Gendler substantially overstates the difference between our spontaneous responses and our explicit judgments: Our explicit judgments do not always change neatly in response to evidence, and our spontaneous responses often do. It may take some time, but when I start parking in a new lot, that precipitates a change in the spontaneous or habitual direction I begin to walk upon leaving the office. When I'm finally told that "LOL" abbreviates "laughing out loud" and not "lots of love", my responses do adjust - either slowly or quickly. And we may be overestimating Juliet's even-handedness if we think that her disposition to judge that the races are intellectually equal was developed primarily in response to, and that it's easily changeable by, the

related judgments (e.g., in Juliet's case about the quality of an applicant or about the reasons Bernard failed her class) that show little parallel between the two cases. (See also note 13.) 
objective state of the evidence. After all, it's wrapped up in her overall politics and liberal values. ${ }^{10}$

Should we say, then, that Juliet does not believe in the intellectual equality of the races? In a way, this is my view: I would say she does not fully believe; it's not quite right to describe her as believing in the intellectual equality of the races. ${ }^{11}$ But then again,

${ }^{10}$ Frankish (2004) - though not primarily in response to cases of the sort discussed in this essay - develops a view similar to Gendler's, based on a distinction between "strand 1 beliefs" (non-conscious, passive, non-linguistic, not apt to be activated in occurrent form) and "strand 2 beliefs" (conscious, can be actively formed, frequently language-involving, apt to be activated in occurrent form). He might suggest that Juliet's racism is strand 1 and her egalitarianism is strand 2. My take on Frankish is more or less the same as my take on Gendler: I worry that the strands are so inextricably intertwined that any division of this sort between them is artificial. (This isn't to deny that there's psychological evidence for some "dual process" theories that posit competition or cooperation between slow, conscious processes and fast, non-conscious ones. See Evans 2008 for a review.) The intuitive appeal of Frankish's distinction may be parasitic on the appeal of the (it seems to me) cleaner and clearer distinction between occurrent judgment and dispositional belief.

${ }^{11}$ I hope it's evident that I don't intend the phrase "fully believe" in this essay to imply having a degree of confidence $\mathrm{p}=1$ in the Bayesian sense. I intend full belief rather as a contrast to being in an "in-between" state of belief, a state in which it is neither entirely accurate to say that one believes nor entirely accurate to say that one fails to believe. Having an intermediate degree of confidence is only one way of being in an 
I think it's also not quite right to say that she fails to believe. It's an in-between case. And thus my view differs also from that of Hunter (manuscript), who simply denies implicit racists the beliefs they avow, ascribing to them, instead, the racist beliefs reflected in their daily behavior. Hunter calls such beliefs "alienated": The believer herself believes them to be false and unjustified, wishes she didn't have them, does not at a higher level endorse them. Hunter explicitly grounds his position in a broad-track dispositional analysis of belief: To "believe that $P$ is to be disposed to act and react as if it were the case that $P$ " (manuscript, p. 3). But given that analysis, why shouldn't he regard cases like Juliet's as in-between cases? Although many of Juliet's actions and reactions are racist, many also are egalitarian - especially her avowals and explicit reasoning. Hunter, then, appears to be the complement of Gendler: Gendler privileges the intellectual aspects of an individual's psychology when it comes to belief ascription, while Hunter privileges, or seems to privilege, the in-the-world spontaneous behavior. But again, the two aspects of our mental life are irremediably intertwined, and I'd suggest we treat both an important part of what it is to believe. Shouldn't belief be seen as what animates both my limbs and my mouth, what shows itself diversely in my actions and my reasoning and my emotional responses, not just in some axed-off subclass of these things?

in-between state of belief, and not the way at issue in this essay (Juliet, for example, may be extremely confident of the intellectual equality of the races and willing to lay long odds, more so than someone who lacks a racist pattern of responding); and conversely full belief may be compatible with something less than absolute certainty in one's betting behavior. (For this reason, I think the common Bayesian practice is misleading in using the phrase "degree of belief" to refer to degree of confidence.) 
Should we ascribe both the belief that the races are intellectually equal and the belief that they are not? This seems to be Gertler's (forthcoming) reaction to examples of this sort - perhaps driven by the thought that either sincere avowal of $P$ or an overall structure of spontaneous reactions in accord with $P$ is sufficient to underwrite belief. ${ }^{12}$ However, I see little to recommend this approach if it's taken naked: It invites only confusion to say simply, without qualification, that Juliet believes both that the races are intellectually equal and that they are not. For comprehensibility we need to add qualifications: In such-and-such respects, Juliet acts and reacts as an egalitarian, in suchand-such respects she does not. This is the clearer answer to questions about what Juliet believes; but it's also the in-between answer. Does it add anything of value - anything besides confusion - to append to this clear answer the claim that Juliet believes both $P$ and its negation? I'm not sure I understand that any better than I would understand, in the case of my conditionally reliable computer, that it is both reliable simpliciter and unreliable simpliciter. Could we say that part of Juliet believes one thing and part believes another? Sometimes people talk this way, but there are serious difficulties with taking such divisions literally. (Like: How do the different parts communicate? How much duplication is there in the attitudes held by the different parts and in the neural systems underlying those attitudes? Such questions are quicksand, especially for an a priori philosopher.)

${ }^{12}$ Gertler appears to express some ambivalence about this view. It may also be possible to interpret her as holding that in cases like Juliet's, the racist holds only the inegalitarian belief. In that case, see my criticism of Hunter above. 
Does Juliet shift back and forth between belief in one proposition and belief in the other? Rowbottom (2007) endorses this treatment of at least some Juliet-like examples. The problem with this approach is that it leaves us without resources to describe Juliet when she's engaged in some neutral task to which race is irrelevant. When she's mowing the lawn, with general propositions about equality far from her mind, and neither seeing nor thinking about anyone of any skin color, which does she believe - that the races are intellectually equal or that they're not? Rowbottom's view leaves us stymied on this point. But of course we need to be able to speak about Juliet globally, not just about her shifting judgments or assumptions in particular individual cases. What's her general attitude? Furthermore, it seems possible for Juliet in single moment both to be having a racist reaction and to be sincerely judging that the races are intellectually equal - for example, in those moments when she is self-consciously trying to compensate for her implicit racism. This is a possibility Rowbottom gives us no means to accommodate.

In cases like Juliet's we should resist the temptation to make punctate, yes-or-no attributions. While she does not fully believe, neither will it do simply to say that she fails to believe. She is somewhere in between. Her dispositions are divided and our attribution must be nuanced. Why should we expect, anyway, simple, punctate models of cognition always to work smoothly, to be anything other than fallible simplifications of the richly complex structure of the mind? ${ }^{13}$

${ }^{13}$ A very different literature in which it seems that people fall into error through insisting on punctate yes-or-no answers to questions about belief is the discussion of Kripke's (1979) puzzle of Pierre: See Goldstein (1993), Schwitzgebel (1997), and Steinberg (manuscript). 
It's not a passion for factually correct metaphysics that animates me here. Actually, I think there's no such thing as factually correct metaphysics. There are just better and worse ways of conceptualizing the world, given our values and the empirical facts. I hope the interest of this essay doesn't depend on that controversial metaphilosophy; but you may not fully understand the argument now coming if you don't see that it's intended as a pragmatic argument.

The central empirical fact is this: A person may be absolutely, completely persuaded of the truth of a proposition, in the sense of reaching a sincere, unequivocal, unmitigated, unqualified, unhesistant judgment, and yet that judgment may fail to penetrate her entire dispositional structure. One may find oneself, against one's will, unable to shuck old habits of thinking and reacting. One may even recognize in advance that these habits will persist, despite one's current sincere judgment which rationally requires their alteration. This is what's going on in the cases of Juliet, of Kaipeng, of $\mathrm{Na}$ and Ben, in some of Zimmerman's and Gendler's and Hunter's cases too - thought about such cases reaches back through philosophical history to Aristotle, Plato, Xunzi, the Stoics, Descartes, Hume, and many others, where it's often conceptualized as the conflict of reason and the passions. But I follow Damasio (1994), Prinz (2004), and others in thinking that the distinction between reason and the passions is considerably overblown; we reason partly through our passions; our passions are implementations of our reason. 
The practical question is this: Do we want to highlight this empirical fact about ourselves - what I'd call the gulf between occurrent judgment and dispositional belief or do we want to marginalize it as an exception? If we treat belief as largely a linguistic phenomenon, as pertaining to explicit reasoning, especially if we think of belief in terms of what we "avow" or "occurrently believe", and if we also think of our actions as mostly guided by our beliefs (in conjunction with our desires), then we do marginalize the gulf: On this marginalizing model, the normal situation is that our actions reflect our beliefs and our beliefs correspond to our judgments. We are thus invited to a noxiously comfortable view of ourselves. We sincerely disavow racism, and we find it easy to assume that our actions reflect this. We say to ourselves that our marriage is worth the effort of preserving, that we believe in God, that our students deserve our respect - and we mean it! The default assumption is that our overall behavior reflects those judgments. It may occur to us - of course it does occur to all of us sometimes and to some of us very often - that our lives may not actually reflect our professed beliefs; but standard philosophical models of the mind encourage us to regard this as an exception.

On the model I propose here, the disconnection between judgment and belief is no exception. Indeed, it can come to seem amazing that for so many of our judgments our dispositions do fall into line almost right away - all in a twinkling, so to speak - so that belief follows immediately. Someone tells me that John has replaced Georgia as department chair. Swiftly, a whole fleet of dispositions change: I'll go to John not Georgia if I have questions about my promotion file, I'll put forms for signature in his box not Georgia's, I'll go down to the chair's office to look for him, etc. Ah, the awesome power of our brains! (Still, didn't I just yesterday find myself heading for the 
chair's office to find Georgia...?) Our morally most important beliefs, however, the ones that reflect our values, our commitments, our enduring ways of viewing the world they're not like this. They change slowly, painfully, effortfully. It takes work to bring one's overall dispositional structure in line with one's broad, life-involving judgments. And unless we do that work and bring about that change, people are quite right to rebuke us for not really or fully or deeply believing what we say we believe.

I say I value family over work. When I stop and think about it, it seems to me vastly more important to be a good father than to craft a few more essays like this one. Yet I'm off to work early, I come home late. I take family vacations and my mind is wandering in the philosopher's ether. I'm more elated by my rising prestige than by my son's successes in school. My wife rightly scolds me: Do I really believe that family is more important? If I knew myself better, I'd have to describe myself as torn and inbetweenish. Or: I sincerely say that those lower than me in social status still deserve my respect; but do I believe this, if I don't live that way? ${ }^{14}$

${ }^{14}$ Cases like somewhat resemble cases of "weakness of the will" or akrasia, much discussed in the philosophical literature on moral psychology and freedom (for a review see Stroud 2008). While I doubt that all cases described as weakness of will can be helpfully described as cases where occurrent judgment diverges from an in-betweenish dispositional belief, I suspect that many can be. Part of the issue may be the breadth of the conditions under which one responds in the "weak" way. If those conditions are broad, and especially if implicit inferences and other judgments seem to be driven by accepting the good or the truth that one outwardly disavows, such cases may helpfully be regarded as in-between cases of believing. 
Why do we care what we believe? Beliefs, as Ramsey (1931) said, are the maps by which we steer. We want to get things right, so we can maneuver successfully through the world. Verbal and intellectual maneuvering is one important sort of maneuvering, but so also is non-verbal and non-intellectual maneuvering; and if we settle ourselves comfortably with the thought that we believe correctly when we are merely disposed to judge correctly, we may often steer quite wrong - literally so, in the case of Ben - so our actions and reactions don't reflect reality as we judge it to be. And also, even independently of the accuracy of our maps, we want to be people of a certain sort. We want to respond consistently and naturally in a way that reflects certain values. Endorsing those values, no matter how sincerely, does not prove their penetration.

From the standpoint of moral psychology, the most important of our beliefs are exactly those that do not change in a twinkling with a sincere judgment. They're the beliefs that shift only gradually and piecemeal. I see no better way to highlight this aspect of our psychology than with a gradualist dispositionalism that rejects sharp lines and enables explicit discussion of our divergent and splintering responses.

vi.

I'll begin the dénouement by considering two objections - or should I say consequences? - of this account. (Objections, of course, are often just consequences thought unappealing.)

First, knowledge. Consider Ben as he's driving blithely toward the closed bridge. In this neglectful moment, is it true to say of him that he believes the bridge is closed? 
Well, here at least are two things he might naturally and rightly say about himself, in retrospect: "I knew the bridge was closed" and "I forgot the bridge was closed". (He may lower his brow with the first statement and raise it with the second.) This juxtaposition may seem strange if you were inclined to think that once someone forgets something they no longer know it. On my account, Ben does not fully believe that the bridge is closed he's in an in-between state of belief, with his dispositions splintered. How does this sit with ordinary language? If we were looking down from above on Ben, as it were - either during this trip or, say, while he's eating breakfast beforehand - would it be natural to say that he believes the bridge is closed? Or that he thinks the bridge is closed (if we may take "think" in this context as colloquial for "believe")? I don't feel a strong pull either way, myself. If anything, there's some impulse to deny that he thinks the bridge is closed, especially when we consider him driving straight for it, but that may be partly due to the contextual saliency of one particular aspect of his dispositional profile.

Now of course many philosophers have said that " $S$ knows that $P$ " implies " $S$ believes that $P$ " (see Armstrong 1973; Lehrer 2000; Williamson 2000). Yes, I am denying that. Attachment to that hoary implication might incline you to insist that Ben believes the bridge is closed. Yet it's not clear that we need to accept that. Maybe knowledge involves something like a capacity and belief something like a tendency: One might have the capacity without the tendency. ${ }^{15}$ I know how to juggle six balls if I have the capacity to do so, even if I usually fail; perhaps also I know that the capital of Burkina Faso is Ouagadougou even if I usually stumble in actual recall; and, more to the point, Juliet knows that the races are intellectually equal even if her black students are

\footnotetext{
${ }^{15}$ I owe this suggestion to David Hunter in conversation.
} 
right in saying she doesn't quite believe it: She has the capacity to respond knowledgeably, even if doesn't usually do so.

My intuitions here may not be entirely idiosyncratic. If recent survey research by Myers-Shulz (2008) stands up, undergraduates are often willing to ascribe knowledge without ascribing belief - and when directly asked, a majority will agree with the statement "it is possible for someone to know something without believing it"; but further research would be necessary to see if they're willing to ascribe knowledge without belief in the Ben and Juliet cases.

Second, momentary belief. Have I now committed myself to saying that people don't believe - or don't fully believe - things that they're prone quickly to forget? At a party, I am introduced to Jerry. I'll forget his name in a minute. But for at least a moment after we're introduced, as his “Hi, I'm Jerry!" echoes through my brain, don't I fully and completely believe that his name is Jerry? Doesn't Ben, for that matter, fully and completely believe that the bridge is closed the moment he reads of its closure (and then again multiple times later, when he reminds himself)? Don't we all, indeed, form slews of micro-beliefs, forgotten in an instant, in our everyday coping with the world about (for example) the positions of cars and hazards around us as we drive down the road?

Dispositions can be fleeting, can come and go. Twigs are fragile when frozen. Francie is primed to snap at her husband right now, and also for fifteen minutes every morning when drinking her coffee. For just a few seconds, my computer is in a state such that it would crash if I pressed the space car. We may distinguish between such passing pronenesses and the corresponding occurrences: The twig needn't break, Francie 
needn't snap, the computer needn't crash. Maybe we can say that I likewise momentarily believe that that guy's name is Jerry, and that Julia momentarily believes that there's a red car to the right. For a minute, our dispositions are all in line. They just don't stay that way. What we have in these cases, perhaps, is not incomplete dispositional alignment but temporary alignment: The dispositions change broadly enough, but they won't stay put. In the case of the red car to the right, such ephemerality might be a good thing. Maybe my problem with retaining Jerry's name is that I'm negotiating the party a bit too much like I negotiate a roadway, coping with near-term hazards and opportunities rather than cultivating long-term knowledge.

But should we dignify such momentary micro-beliefs with the term "belief”? Consider the "Jerry" case. Maybe we should break to some extent from (what I take to be) ordinary usage and deny me the full belief even as I say "Nice to meet you, Jerry!" In some sense, it seems, I am not even in that moment disposed to respond to him as "Jerry", attribute him that name, in a sufficiently broad range of situations.

A dispositional approach to belief can allow for - indeed explain - both the belief-attributing and belief-denying inclinations here. The key is in the interpretation of the relevant counterfactual conditionals. Consider the following disposition (proneness): If down in the hotel lobby, someone were to ask me Jerry's name (pointing to him across the room), the right answer would strike me. Now consider: Do I have that disposition the moment I say "Nice to meet you, Jerry!"? It depends on what one loads into the antecedent of the conditional. If we assume my state of mind in the lobby to be very much as it is now, then yes. "Jerry" is big in my mind now; it is big in my mind in the counterfactual situation. If, on the other hand, we don't hold the centrality of "Jerry" 
constant across the counterfactual situations - if we assume that my mind has returned to a more neutral, less "Jerry"-ish state, then no, I'm not disposed correctly to recall his name in the lobby. Since we have considerable leeway in evaluating counterfactual conditionals, we have corresponding leeway in the ascription of pronenesses. ${ }^{16}$ I hesitate to say, then, that there is a definite fact of the matter, at the moment I greet Jerry, whether I have the panoply of dispositions necessary to underwrite genuine belief.

Let it be a choice of temperament, then, or a practical decision guided by the interests driving the ascription or denial of belief in the particular situation. For example, if this so-called "Jerry" is an imposter (Dan Dennett, say, pretending to be Jerry Fodor), and you are wondering whether I'm onto Dan's tricks - if the central issue is one of truthfulness - then there may be no great infelicity in simply saying that the chance of mendacity had not crossed my mind: I believed him when he said his name was "Jerry". On the other hand, if it's the real Jerry in the flesh and you are principally concerned not about deception but about my long-term dispositions - about whether the belief has "sunk in" - you may wish to describe my cognitive situation in a more nuanced way.

vii.

In any case, it is evident that many of our most important beliefs change only incompletely, transiently, or gradually. Sometimes we have to work to bring our overall

${ }^{16}$ My emphasis on counterfactuals here shouldn't be taken necessarily as an endorsement of a counterfactual analysis of dispositions. On that issue see Prior 1985; Martin 1994; Mumford 1998; Fara 2005. 
dispositional structure in line with our occurrent judgments. This isn't a kind of work that many of us like, and it's a kind of work it may be hard to see the need of on a dropthe-belief-in-the-box model of judgment and understanding. It's easy to say "I believe in truth of the Christian Bible" or "I think my marriage worth the effort to sustain" but to live these beliefs, to shape one's tendencies and pronenesses so that it is useful to say that one - in any steady, meaningful way - fully believes these things, is no simple matter. Genuine belief does not always flow passively from sincere judgment. Most English speakers, and most English-speaking philosophers, do not I think fully appreciate this, in part due to our too-linguistic, too-avowal-oriented view of belief - a myopia both reflected in and reinforced by philosophers' unhappy tendency to refer to judgments as "occurrent beliefs". We should embrace an ontology that treats belief as purely dispositional. There are no occurrent beliefs.

To profess belief in God, or the value of one's marriage, or the unobjectionableness of death, is not entirely - perhaps not even primarily - a matter of reporting some pre-existing inner state or expressing some fully formed belief about the world. As Brandom (1994), Moran (2001), McGeer and Pettit (2002), and others have emphasized, avowal is commissive, entailing a certain amount of forward-looking selfregulation. It's partly prospective, something a speaker must work to make true, contingent in part on the speaker's ongoing commitment to corral contrary inclinations. This commissive, prospective element can tinge the utterances with anxiety: To make them true, you have to live up to them. It's exactly because we so often fail to live 
according to our avowals that we need a clear distinction between judgment and belief. ${ }^{17}$

${ }^{17}$ My thoughts on this topic have been much informed by conversations with Tori McGeer and Ted Preston. The views expressed (committed to?) here are not, I hope, entirely unlike the views found in some of their work (esp. McGeer 1996; McGeer and Pettit 2002; Preston 2005), as well as that of H.H. Price (1969). Thanks also to helpful conversations with Jonathan Adler, Tamar Gendler, Brie Gertler, Peter Graham, Linus Huang, David Hunter, Krista Lawlor, Coleen Macnamara, Darrell Rowbottom, Jesse Steinberg, Zoltan Szabo, Aaron Zimmerman, and readers of my blog, as well as audiences at the 2005 Canadian Philosophical Association meeting and at Australian National University in 2008. I have explored related themes in Schwitzgebel (2002) and McGeer and Schwitzgebel (2006). This essay descends from a manuscript of a similar name discussed by Gendler (forthcoming-b) and Gertler (forthcoming). 


\section{References:}

Armstrong, D.M. (1973). Belief, Truth, and Knowledge, London: Cambridge.

Audi, Robert (1994). Dispositional Beliefs and Dispositions to Believe, Noûs 28: 419434.

Bach, Kent (1981). An Analysis of Self-Deception, Philosophy and Phenomenological Research 41: 351-370.

Brandom, Robert B. (1994). Making It Explicit, Cambridge, MA: Harvard.

Burge, Tyler (1979). Individualism and the Mental, Midwest Studies in Philosophy 4: 73-121.

Carnap, Rudolf (1947/1956). Meaning and Necessity, Chicago: University of Chicago. Crane, Tim (2001). Elements of Mind, Oxford: Oxford.

de Sousa, Ronald B. (1971). How to Give a Piece of Your Mind: Or, the Logic of Belief and Assent, Review of Metaphysics 25: 52-79.

Evans, Jonathan St. B. T. (2008). Dual Processing Accounts of Reasoning, Judgment, and Social Cognition. Annual Review of Psychology 59: 255-278.

Fara, Michael (2005). Dispositions and Habituals, Noûs 39: 43-82.

Fodor, Jerry A. (1968). Psychological explanation, New York: Random House.

Fodor, Jerry A. (1987). Psychosemantics, Cambridge, MA: MIT.

Frankish, Keith (2004). Mind and Supermind, Cambridge: Cambridge.

Gendler, Tamar Szabó (forthcoming-a). Alief and Belief. Journal of Philosophy. Gendler, Tamar Szabó (forthcoming-b). Alief in Action (and Reaction). Mind \&

\section{Language.}


Gertler, Brie (forthcoming). Do We Determine What We Believe by Looking Outward? in Self-Knowledge, ed. Anthony Hatzimoysis, Oxford: Oxford.

Goldstein, Lawrence (1993). The Fallacy of the Simple Question. Analysis 53: 178-181. Heil, John (2003). From an Ontological Point of View, Oxford: Oxford.

Hunter, David (manuscript). Belief, Alienation, and Intention.

Kim, Jaegwon (1998). Philosophy of Mind, Oxford: Westview.

Kripke, Saul A. (1979). A Puzzle about Belief, in Meaning and Use, ed. A. Margalit, Dordrecht: Reidel.

Lawlor, Krista (manuscript). Knowing What One Believes.

Lehrer, Keith (2000). Theory of Knowledge, $2^{\text {nd }}$ ed., Boulder, CO: Westview.

Lewis, David (1986). Philosophical Papers, vol. 2, New York: Oxford.

Lycan, William G. (1986). Tacit Belief in Belief, ed. R. J. Bogdan, Oxford: Clarendon: $61-82$.

Martin, C.B. (1994). Dispositions and Conditionals, Philosophical Quarterly 44: 1-8.

McGeer, Victoria, and Philip Pettit (2002). The self-regulating mind, Language \&

Communication 22: 281-299.

McGeer, Victoria and Eric Schwitzgebel (2006). Disorder in the Representational Warehouse, Child Development 77: 1557-1562.

Moran, Richard (2001). Authority and estrangement, Princeton: Princeton.

Mumford, Stephen (1998). Dispositions, Oxford: Oxford.

Myers-Shultz (2008). Is Belief Required for Knowledge? Blog post at http://experimentalphilosophy.typepad.com/experimental_philosophy/2008/09/isbelief-requi.html. 
Nichols, Shaun, and Stephen P. Stich (2003). Mindreading, Oxford: Clarendon.

Nozek, Brian A., Anthony G. Greenwald, and Mahzarin R. Banaji (2007). The Implicit Association Test at Age 7: A Methodological and Conceptual Review, in $\underline{\text { Social }}$ Psychology and the Unconscious, ed. J.A. Bargh. New York: Psychology Press. Peacocke, Christopher (1999). Being Known. Oxford: Oxford.

Price, H.H. (1969). Belief, London: George Allen \& Unwin.

Preston, Ted M. (2005). Bridging the Gap Between Normative Beliefs and Actions, Ph.D. Dissertation, University of California at Riverside.

Prior, Elizabeth (1985). Dispositions, Aberdeen: Aberdeen.

Ramsey, Frank P. (1931). The Foundations of Mathematics, and Other Logical Essays, London: Routledge \& Kegan Paul.

Rowbottom, Darrell P. (2007). “In-Between Believing” and Degrees of Belief, Teorema 26: 131-137.

Ryle, Gilbert (1949). The Concept of Mind, New York: Barnes \& Noble.

Schwitzgebel, Eric (1997). Words About Young Minds, Ph.D. Dissertation, University of California at Berkeley.

Schwitzgebel, Eric (2001). In-Between Believing, Philosophical Quarterly 51: 76-82.

Schwitzgebel, Eric (2002). A Phenomenal, Dispositional Account of Belief, Nous 36: 249-275.

Schwitzgebel, Eric (2006). Belief, Stanford Encyclopedia of Philosophy, August 14, 2006.

Sellars, Wilfrid (1969). Language as Thought and as Communication, Philosophy \& Phenomenological Research 29: 506-527. 
Shah, Nishi, and J. David Velleman (2005). Doxastic deliberation, Philosophical Review 114: $497-534$.

Steinberg, Jesse (manuscript). Two Solutions to Kripke's Puzzle.

Stroud, Sarah (2008). Weakness of Will, Stanford Encyclopedia of Philosophy, May 14, 2008.

Swinburne, Richard (1985). Thought, Philosophical Studies 48: 153-171.

Williamson, Timothy (2000). Knowledge and Its Limits, New York: Oxford.

Zimmerman, Aaron (2007). The Nature of Belief, Journal of Consciousness Studies 14 (no. 11): 61-82. 